Chapter 19

\title{
Recent Advances on Soybean Isoflavone Extraction and Enzymatic Modification of Soybean Oil
}

\author{
Masakazu Naya and Masanao Imai \\ Additional information is available at the end of the chapter \\ http://dx.doi.org/10.5772/52603
}

\section{Extraction of soybean isoflavone}

\subsection{Soybean isoflavones and attractive potential of supercritical carbon dioxide $\left(\mathrm{SCCO}_{2}\right)$}

Isoflavones produced from bioresources are gaining attention as attractive components in food supplements. Isoflavones are heterocyclic phenols with a structure very similar to that of estrogens. Isoflavone displays like estrogens and has anti estrogen activity; it influences sex hormone metabolism and related biological activity $[1,2]$ and prevents osteoporosis $[3,4]$, arteriosclerosis [5], dementia [2], and cancer [6,7].

Soybeans contain 12 different isoflavones classified into two components, glycosides and aglycons. Glycoside isoflavone has a glucose chain in its molecular structure; aglycon isoflavone does not have a glucose structure.

Ninety-three percent of isoflavones are produced and stored as glycoside. Therefore, in practical separation processes, glycoside isoflavones were the major fraction and were recognized as the main target group rather than aglycons. This article focuses on daidzin, genistin and glycitin as typical glycosides. Their aglycons (i.e., daidzein, genistein and glycitein) were examined for comparison. The aglycons have no glycoside chain; their chemical structure is depicted in Fig. 1.

Methods of extracting isoflavones from soybean have been previously examined by using organic solvent [8], pressurized liquid [9], ultrasound [10,11], and supercritical carbon dioxide [12-16]. Supercritical carbon dioxide has been the favorite extraction medium for many food functional components, i.e. caffeine [17-20], capsaicin [21,22], carotenoids [23-26], polyphenol [27-30], aspirin [31], and coenzyme Q10 [32]. 
In general, the solubility of polar components in the $\mathrm{SCCO}_{2}$-only system was very low because carbon dioxide has non-polar characteristics. The solubility of polar components has been well enhanced by adding polar components to the $\mathrm{SCCO}_{2}$ system. The added component was referred to as an entrainer. Ethanol was effectively employed as an entrainer for extraction and applied to caffeine [17,19], capsaicin [21], catechin [27], epicatechin [28], aspirin[31], and coenzyme Q10 [32]. Rostagno et al. (2002) successfully extracted large amounts of isoflavones from soybean flour by using methanol aqueous solution as an entrainer [14]. Zuo et al. (2008) also extracted isoflavones from soybean meal by using methanol [16].

To design practical separation processes using $\mathrm{SCCO}_{2}$, it is necessary to establish a reliable database of the entrainer's enhancement effects. This would facilitate both the choice of a suitable entrainer for an objective component and the quantitative evaluation of separation yield of a target component in actual processes.

In this chapter, we demonstrate the solubility of isoflavones in $\mathrm{SCCO}_{2}$ with ethanol added. The solubility in an $\mathrm{SCCO}_{2}$-only system was also measured for comparison. The effect of the entrainer on solubility is discussed with the hydrophobicity of guest components evaluated from their molecular structure. The thermodynamic relationship between the solubility and the parameter indicated a non-ideal state in $\mathrm{SCCO}_{2}[33]$.

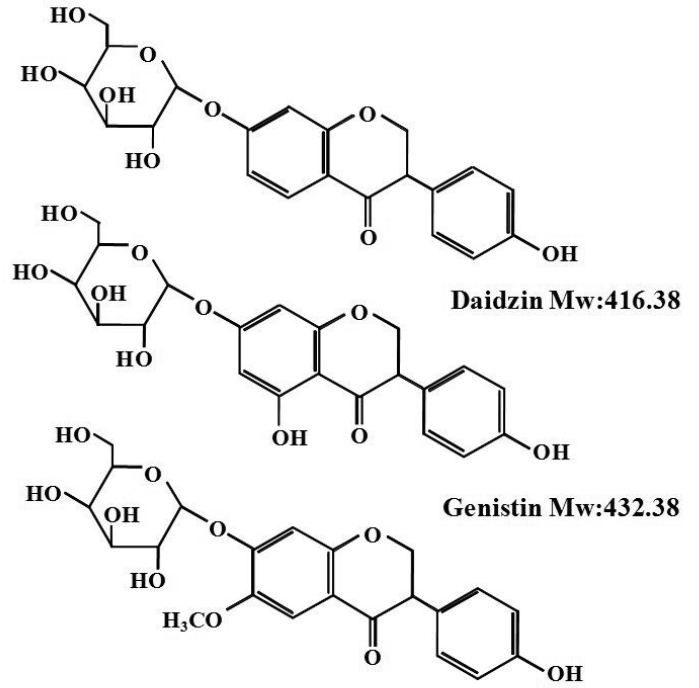

Glycitin Mw:446.40<smiles>O=C1c2ccc(O)cc2OCC1c1ccc(O)cc1</smiles>

Daidzein Mw:256.24<smiles>O=C1c2c(O)cc(O)cc2OCC1c1ccc(O)cc1</smiles>

Genistein Mw:270.24<smiles>COc1cc2c(cc1O)OCC(c1ccc(O)cc1)C2=O</smiles>

Glycitein Mw:284.26

Figure 1. Chemical structure of isoflavones in soybean 


\subsection{Solubility of isoflavones and effect of entrainer}

\subsubsection{Experimental}

A circulation flow of $\mathrm{SCCO}_{2}$ was employed for the experimental extraction system (JASCO Co., Ltd., Tokyo) as presented in Fig. 2. The $1.0 \mathrm{~mL}$ stainless-steel extraction vessel was installed in an extraction line with a total volume of $19.8 \mathrm{~mL}$. The extraction temperature was set at $313 \mathrm{~K}$. The pressure range was from 15 to $25 \mathrm{MPa}$. The $\mathrm{CO}_{2}$ volumetric flow rate in the extraction line was adjusted to a constant $5 \mathrm{~mL} / \mathrm{min}$ at $15 \mathrm{MPa}$ and $25 \mathrm{MPa}$.

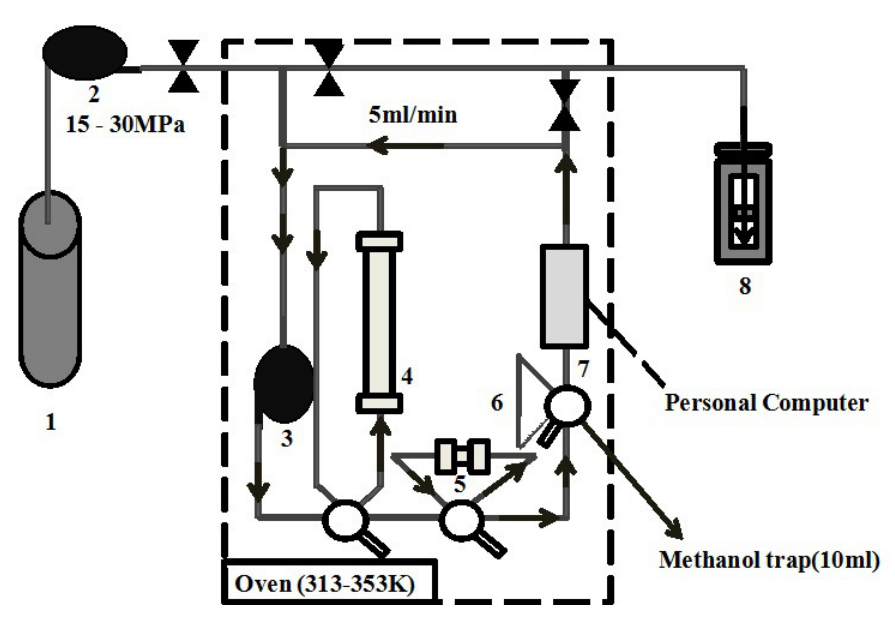

Figure 2. Schematic of experimental apparatus used in measuring the solubility in $\mathrm{SCCO}_{2}$. (1) $\mathrm{CO}_{2}$ gas cylinder, (2) compressor, (3) circulating pomp, (4) diffusion column, (5) extraction vessel, (6) sample loop with a methanol trap, (7) UVdetector, and (8) exhaust regulator

\subsubsection{Solubility of isoflavones}

Table 1 summarizes the solubility of isoflavones in the $\mathrm{SCCO}_{2}$-single system. In general, the isoflavones were hardly extracted by the $\mathrm{SCCO}_{2}$-single system. In particular, the solubility of glycoside isoflavones was very low it could not be detected by HPLC.

\begin{tabular}{clc}
\hline & Isoflavone & \multicolumn{1}{c}{$\begin{array}{c}\text { Solubility } \\
\text { [mol-isoflavone/mol-sCCO }\end{array}$} \\
\hline Glycoside & Daidzin & not detected \\
\cline { 2 - 3 } & Genistin & not detected \\
\cline { 2 - 3 } & Glycitin & not detected \\
\hline Aglycon & Daidzein & $5.14 \times 10^{-10}$ \\
\cline { 2 - 3 } & Genistein & $6.38 \times 10^{-10}$ \\
\hline & Glycitein & not detected \\
\hline
\end{tabular}

Table 1. The solubility of isoflavones in pure $\mathrm{SCCO}_{2}$ without ethanol at $313 \mathrm{~K}, 25 \mathrm{MPa}$ 


\subsubsection{Effect of entrainer (ethanol) on solubility of isoflavones}

Figure 3 presents the solubility of daidzin (as glycoside) and daidzein (as aglycon) in the $\mathrm{SCCO}_{2}$ and ethanol binary system. Solubility $\mathrm{S}$ was increased remarkably by increasing the molar fraction of ethanol, M. This trend was also obtained at 25MPa. The solubility of genistin (as glycoside) and genistein (as aglycon) presented in Fig. 4 also exhibited the same trend. This remarkable influence of the molar fraction of ethanol also seemed to be similar between glycitin (as glycoside) and glycitein (as aglycon) (Fig. 5). The results indicated that the solubility of hydrophilic glycoside isoflavones (daidzin, genistin, and glycitin) depended more strongly on the molar fraction of ethanol.

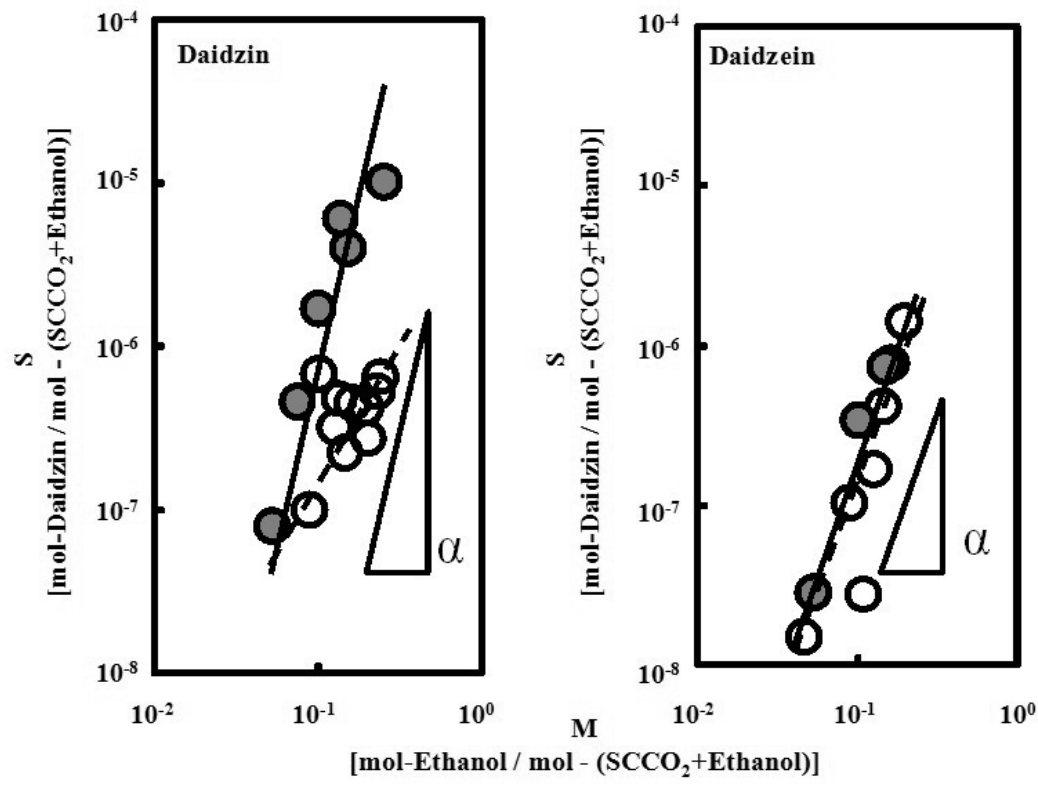

Figure 3. Solubility of daidzin and daidzein in $\mathrm{SCCO}_{2}$ and ethanol binary system at 15 and $25 \mathrm{MPa}$ and at $313 \mathrm{~K}, 015$ $\mathrm{MPa}, 25 \mathrm{MPa}$.

As seen in Fig. 3, the solubility of daidzin at $25 \mathrm{MPa}$ was far greater than that at $15 \mathrm{MPa}$. Ethanol depended more heavily on the molar fraction at $25 \mathrm{MPa}$ than at $15 \mathrm{MPa}$. In contrast to genistin and genistein, the solubility was almost the same in spite of the increased pressure (Fig. 4). The dependency on the molar fraction of ethanol was similar for $25 \mathrm{MPa}$ and $15 \mathrm{MPa}$. 

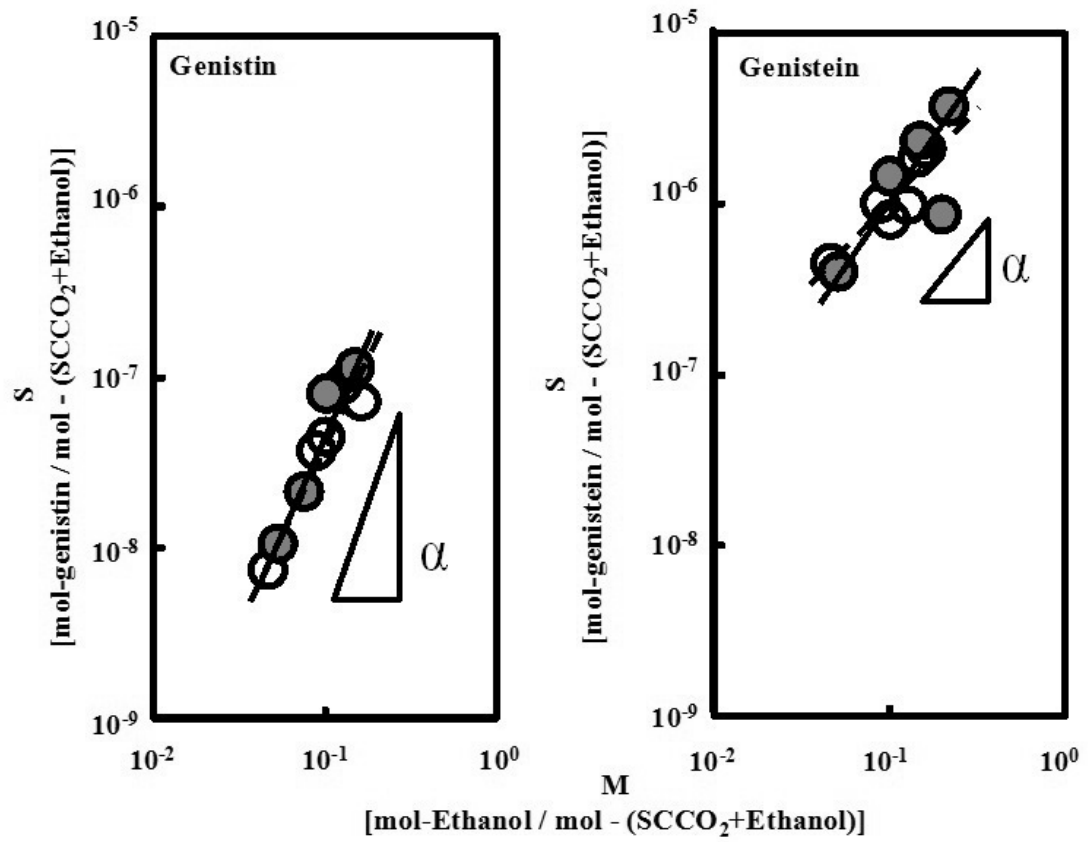

Figure 4. Solubility of genistein into $\mathrm{SCCO}_{2}$ and ethanol binary system at 15 and $25 \mathrm{MPa}$ and at $313 \mathrm{~K} \circ 15 \mathrm{MPa}$, $25 \mathrm{MPa}$.

\begin{tabular}{|c|c|c|}
\hline & \multirow[t]{2}{*}{ Isoflavones } & Solubility ratio \\
\hline & & $\equiv \frac{\text { The solubility at } 25 \mathrm{MPa}}{\text { The solubility at } 15 \mathrm{MPa}}[-]$ \\
\hline \multirow[t]{3}{*}{ Glycoside } & Daidzin & 6.3 \\
\hline & Genistin & 1.8 \\
\hline & Glycitin & - \\
\hline \multirow[t]{3}{*}{ Aglycon } & Daidzein & 1.3 \\
\hline & Genistein & 1.8 \\
\hline & Glycitein & - \\
\hline The solubility were referr & 3 and Fig. 4. & \\
\hline
\end{tabular}

Table 2. The solubility ratio of isoflavones in $\mathrm{SCCO}_{2}$ with ethanol at $313 \mathrm{~K}$. The solubility were referred from Fig. 3 and Fig. 4. The molar fraction of ethanol $\mathrm{M}$ was set at 0.1 .

The solubility ratio was defined as the solubility of $25 \mathrm{MPa}$ divided by that of $15 \mathrm{MPa}$. The molar fraction of ethanol was set at 0.10, as evaluated from Figs. 3 and 4, and summarized in Table 2. In the case of daidzin, the solubility ratio was calculated as 6.3 fold. It was especially high among the tested isoflavones, i.e. 1.8 (Genistin), 1.3 (Daidzein), and 1.8 (Genistein). The solubility of daidzin was strongly affected by extraction pressure in four tested isoflavones. 


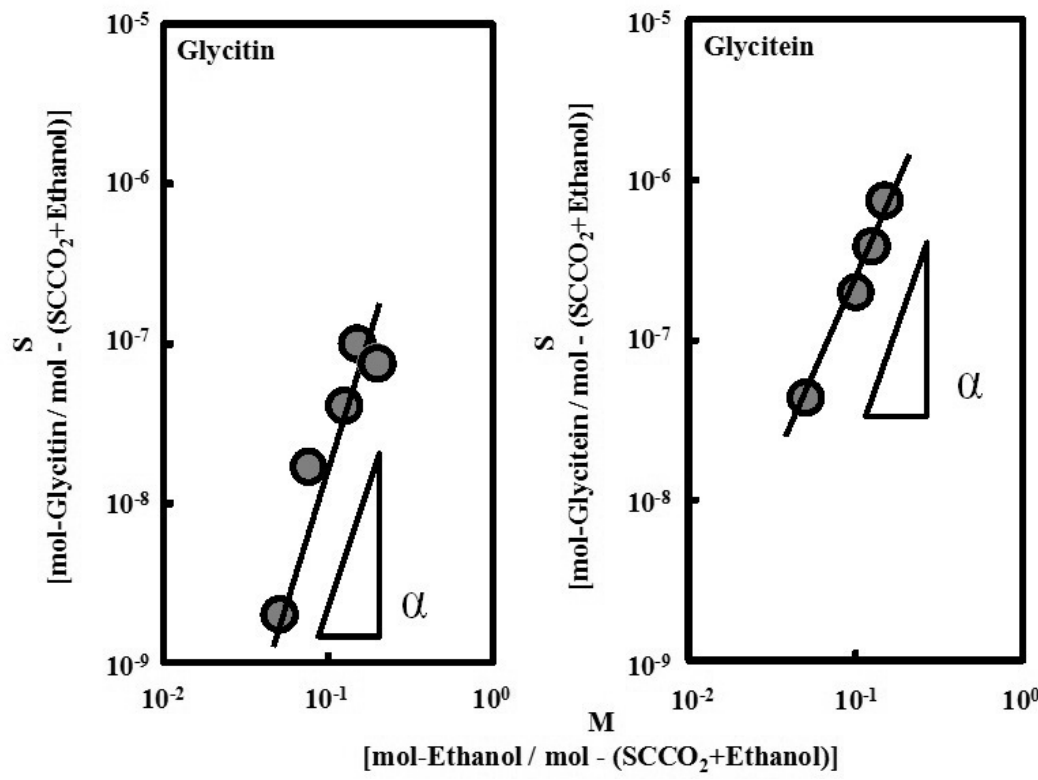

Figure 5. Solubility of glycitin and glycitein in $\mathrm{SCCO}_{2}$ and ethanol binary system at $25 \mathrm{MPa}$ and $313 \mathrm{~K}$.

The solubility of daidzin (glycoside) exceeded that of daidzein (aglycon). This trend appeared especially strong in daidzin, in contrast to that of other isoflavones. For other isoflavones, glycosides (genistin and glycitin) were less soluble than the corresponding aglycons (genistein and glycitein) due to their hydrophilic nature and the glycoside chain in their molecular structure. The detailed reasons for the special behavior of daidzin and daidzein are not clear at present.

The enhanced solubility after adding ethanol was preliminarily evaluated by the logarithmic dependency of $\alpha$ on the molar fraction of ethanol $\mathrm{M}$. The solubility $\mathrm{S}$ was proportional to the $\alpha^{\text {th. }}$ power of $\mathrm{M}$ as indicated in empirical equation Eq. (1).

$$
\mathrm{S} \propto \mathrm{M}^{\alpha}
$$

The power term $\alpha$ is summarized in Table 3. The power term $\alpha$ of glycoside isoflavones (daidzin, genistin, glycitin) at both $15 \mathrm{MPa}$ and $25 \mathrm{MPa}$ often exceeded 3.0. As presented in Table 4, glycoside isoflavones are commonly more hydrophilic than their corresponding aglycons. Additive ethanol concentration in $\mathrm{SCCO}_{2}$ strongly affected the solubility of hydrophilic isoflavones. The power term $\alpha$ of daidzein (aglycon) exceptionally exceeded 3.0 in spite of its hydrophobic nature. The detailed mechanism of solubilization must be investigated further. It may be related to a slight difference of molecular structure. 


\begin{tabular}{|c|c|c|c|c|c|}
\hline \multirow[b]{2}{*}{ Glycoside } & \multirow{2}{*}{$\begin{array}{l}\text { Isoflavones } \\
\text { Daidzin }\end{array}$} & \multicolumn{2}{|c|}{$\mathbf{a}(15 \mathrm{MPa})[-]$} & \multicolumn{2}{|c|}{$a(25 \mathrm{MPa})[-]$} \\
\hline & & 3.42 & $\mathrm{R}^{2}=0.708$ & 3.69 & $R^{2}=0.907$ \\
\hline & Genistin & 3.08 & $R^{2}=0.996$ & 3.41 & $R^{2}=0.932$ \\
\hline & Glycitin & & data & 3.27 & $R^{2}=0.852$ \\
\hline \multirow[t]{3}{*}{ Aglycon } & Daidzein & 3.17 & $R^{2}=0.967$ & 3.02 & $R^{2}=0.975$ \\
\hline & Genistein & 0.728 & $R^{2}=0.985$ & 1.72 & $R^{2}=0.999$ \\
\hline & Glycitein & \multicolumn{2}{|c|}{ No data } & 1.85 & $R^{2}=0.988$ \\
\hline
\end{tabular}

Table 3. Power term a of Eq.(1) on the solubility enhancement

The dependency on the molar fraction of ethanol increased at higher pressures. The solubilities of genistin and genistein are almost the same in spite of the pressure change. The dependency on molar fraction of ethanol was also similar, suggesting that the solubility depended heavily on the amount of ethanol added. Power term $\alpha$ became large under $\mathrm{SCCO}_{2}$ at higher pressures, except for daidzein.

\begin{tabular}{lll}
\hline & Isoflavones & Log P [-] \\
\hline Glycoside & Daidzin & 0.232 \\
\cline { 2 - 3 } & Genistin & 0.837 \\
\cline { 2 - 3 } & Glycitin & 0.230 \\
\hline Aglycon & Daidzein & 1.29 \\
\cline { 2 - 3 } & Genistein & 2.09 \\
\cline { 2 - 3 } & Glycitein & 1.85 \\
\hline
\end{tabular}

Table 4. The evaluated Log P of isoflavones

\subsection{Conclusion}

Solubilities of six different isoflavones were measured in an $\mathrm{SCCO}_{2}$ system with ethanol added. Ethanol effectively increased the solubility of isoflavones. It served as an attractive entrainer with $\mathrm{SCCO}_{2}$. The power term in the molar fraction of ethanol exceeded 3.0. The enhancement was remarkable in more hydrophilic isoflavones (daidzin, genistin, and glycitin). We experimentally determined the hydrophobicity $(\log P)$ [34] of isoflavones from the equilibrium constant between 1-octanol and water. The hydrophobicity of daidzin was lowest among the tested isoflavones, and the enhancement due to adding ethanol was the highest.

Soybean and other natural bioresources are abundant sources of various glycoside isoflavones. Isoflavones will be successfully extracted from these sources for practical application by $\mathrm{SCCO}_{2}$ with ethanol added. 


\section{Enzymatic modification of soybean lipid by lipase and immobilized lipase}

\subsection{Introduction}

Soybean is beneficial in food applications and is attractive as a bioresource for functional components. Soybean contains many proteins and much oil. Furthermore, many functional components, isoflavone [35], lecithin [36], saponin [35,37], and oligosaccharide, [38,39] are desirable for promoting human health.

Soybean oil generally contains $52 \%$ linoleic acid, $22 \%$ oleic acid, $10 \%$ palmitic acid, and $8 \%$ linolenic acid. Soybean oil can be readily hydrolyzed by lipase like other vegetable oils. The produced fatty acids have several applications such as in manufacturing soaps, surfactants, and detergents, and in food.

Lipases have received attention for lipid modification [40-42]. They are used in fields such as food engineering, detergents, beverages, cosmetics, biomedical uses, and the chemical industry. They catalyze hydrolysis, alcoholysis, acidolysis, amidolysis, and esterification in the food and pharmaceutical industries [43-48]. Lipid modifications (hydrolysis, esterification, etc.) often lead to better quality products due to high specificity and selectivity of the lipase. Immobilized lipases have been applied in various hydrophobic reactions [42,49-51]. Reactivity of immobilized lipase was affected by physicochemical factors in reaction media $[52,53]$. A hydrophobic material is especially favorable for quick initiation of hydrophobic enzymatic reaction due to the easy diffusion of the substrate in the inner pores of the carrier. Previously, hydrophilic gels and solid porous carriers were often employed even for hydrophobic substrate reactions. Detailed technical data focused on carriers to quickly initiate hydrophobic enzymatic reactions, and high yield repeated-use immobilized enzymes are necessary in industrial design of hydrophobic enzyme reactions [54-56].

\subsection{Process chemistry of soybean oil modification}

Vegetable oils (olive oil [40,42]) can be hydrolyzed to produce monoglyceride, diglyceride, free fatty acids, and glycerol. Free fatty acids are value-added products because of their wide applications in surfactants, soap manufacturing, the food industry, and biomedical uses. The conventional and industrial method of oil hydrolysis has been carried out using a chemical catalyst at high temperatures and pressure. However, successful enzymatic hydrolysis reactions are possible without high temperatures and pressure.

Dalla, R. C. et al. investigated the continuous production of fatty acid ethyl esters from soybean oil in compressed fluids, namely carbon dioxide, propane, and n-butane, using immobilized Novozym 435 as a catalyst [57]. Their work evaluated the effects of some process variables on the production of fatty acid ethyl esters from soybean oil in compressed propane using Novozym 435 as a catalyst in a packed-bed reactor. In contrast to using carbon dioxide and n-butane, their results indicated that lipase-catalyzed alcoholysis was achieved 
in a continuous tubular reactor in compressed propane with high reaction yields at mild temperatures $\left(70^{\circ} \mathrm{C}\right)$ and pressures $(60 \mathrm{bar})$ and with short reaction times. The results demonstrated that lipase-catalyzed alcoholysis in a packed-bed reactor using compressed propane as solvent was promising as a potential alternative to conventional processes. It may be possible to manipulate process variables as well as reactor configurations to achieve acceptable yields.

Guan, F. et al. investigated the transesterification of a combination of two lipases [58]. A combination of two lipases was employed to catalyze methanolysis of soybean oil in an aqueous medium during production process. The aqueous medium was a mixture of $7 \mathrm{~g}$ soybean oil, methanol in various molar ratios (3:1, 4:1, 5:1, 6:1, and 9:1; methanol : oil) and $2 \mathrm{~mL}$ (550U per $\mathrm{mL}$ ) P. pastoris-Rhizomucor miehei lipase supernatant of fermentation broth (a water content of $28.6 \mathrm{wt} \%$, implies the total $\mathrm{H}_{2} \mathrm{O} /$ weight of oil). The two lipase genes were cloned from fungal strains Rhizomucor miehei and Penicillium cyclopium, and each was expressed successfully in Pichia pastoris. Activities of the 1,3-specific lipase from R. miehei and the non-specific mono- and diacylglycerol lipase from P. cyclopium were 550U and $1545 \mathrm{U}$ per $\mathrm{mL}$ respectively. Enzymatic properties of these supernatants of fermentation broth (liquid lipase) were continuously stable at $4^{\circ} \mathrm{C}$ for more than 3 months. Under optimized conditions, the ratio of production conversion after $12 \mathrm{~h}$ at $30^{\circ} \mathrm{C}$, using $R$. miehei alone, was $68.5 \%$. When $R$. miehei was assisted by adding $P$. cyclopium, the production conversion ratio increased to $95.1 \%$ under the same reaction conditions. The results suggested that combination of lipases with different specificity, for enzymatic conversion of more complex lipid substrates, is a potentially useful strategy to realize high conversion.

\subsubsection{Hydrolysis}

In hydrolysis, water is used to break the bonds of certain substances. In biotechnology and living organisms, these substances are often polymers. In hydrolysis involving an ester link between two amino acids in a protein, the products include the hydroxyl $(\mathrm{OH})$ group, which becomes carboxylic acid with the addition of the remaining proton.

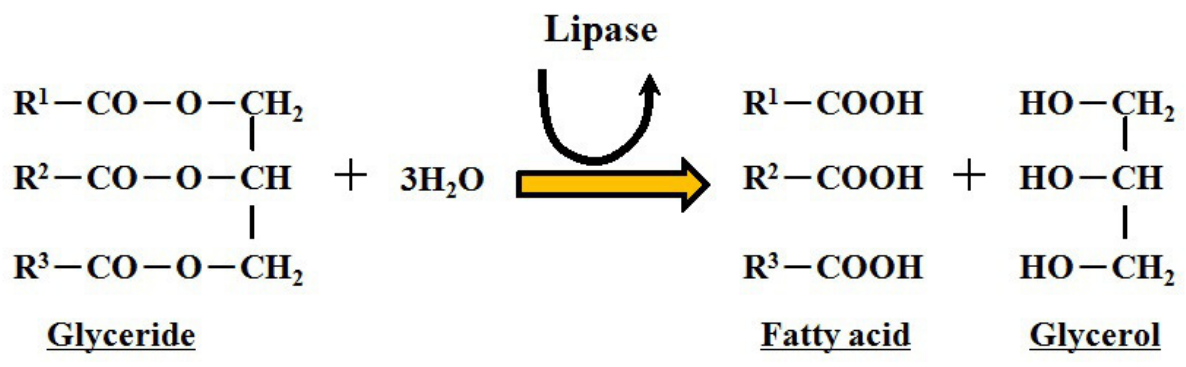

Figure 6. Hydrolysis of triglyceride catalyzed by lipase 
Hydrolysis reactions in living organisms are performed with the help of catalysis by a class of enzymes known as hydrolases. The biochemical reactions that break down polymers such as proteins (peptide bonds between amino acids), nucleotides, complex sugars and starch, and fats are catalyzed by hydrolases. Within this class, lipases, amylases, and proteinases hydrolyze fats, sugars and proteins, respectively (Fig. 6).

The hydrolysis of vegetable oils is also industrially important. The complete hydrolysis of triglycerides will produce fatty acids and glycerol. These fatty acids find several applications such as in manufacturing soaps, surfactants, and detergents, and in the food industry. Since there are many kinds of natural substrates, the high specificity and selectivity of the enzymes used in the hydrolysis reaction will lead to products of better quality. Lipase has been used in the hydrolysis of different oils and fats to produce free fatty acids.

Ting, W-J. et al. investigated soybean hydrolysis by immobilized lipase in chitosan beads [59]. Their work is the culmination of their research efforts to develop an enzymatic/acidcatalyzed hybrid process for production with a view to utilizing edible and off-quality soybean oils as feedstock. They achieved a higher degree of hydrolysis. The reaction was carried out at $40^{\circ} \mathrm{C}$ for $12 \mathrm{~h}$ using binary immobilized Candida rugosa lipase. The conversion of free fatty acid increased rapidly from 0 to $5 \mathrm{~h}$. After $5 \mathrm{~h}$, the conversion of free fatty acid did not increase significantly. Almost $88 \%$ of the oil was hydrolyzed after $5 \mathrm{~h}$, indicating that the feedstock for the acid-catalyzed synthesis was easily obtained by the hydrolysis of soybean oil using the binary immobilized lipase. The feedstock for acid-catalyzed production obtained after $5 \mathrm{~h}$ of enzymatic hydrolysis of oil contained $12 \%$ triglyceride and $88 \%$ monoglyceride, diglyceride, and free fatty acid. Problems linked to higher free fatty acid contents can be overcome by using the enzymatic/acid-catalyzed hybrid process proposed in their study. Therefore, any unrefined oil that contains different levels of free fatty acid can be used.

\subsubsection{Esterification}

Esterification is the chemical process of making esters, which are compounds of the chemical structure R-COOR', where $\mathrm{R}$ and R' are either alkyl or aryl groups (Fig. 7). The esterification process has a broad spectrum of uses from preparing highly specialized esters in chemical laboratories to producing millions of tons of commercial ester products. These commercial compounds are manufactured by either a batch or a continuous synthetic process. The batch procedure involves a single pot reactor that is filled with the acid and alcohol reactants.

Sugar fatty acid esters are widely used as non-ionic surfactants in cosmetic and food applications. Current chemical production is based on high-temperature esterification of sugars and fatty acids, using an alkaline catalyst leading to a mixture of products. Alternatively, sugar fatty acid esters can be obtained by fermentation as so-called biosurfactants. The direct esterification of sugar and fatty acid using isolated enzymes (mainly lipases) is hampered by the low solubility of sugars in most organic solvents. Good conversions can be 
achieved in pyridine, but this solvent is incompatible with food applications. Other solutions are based on the use of alkylglycosides or protected sugars like isopropylidene or phenylboronic acid derivatives, which require additional synthesis steps.

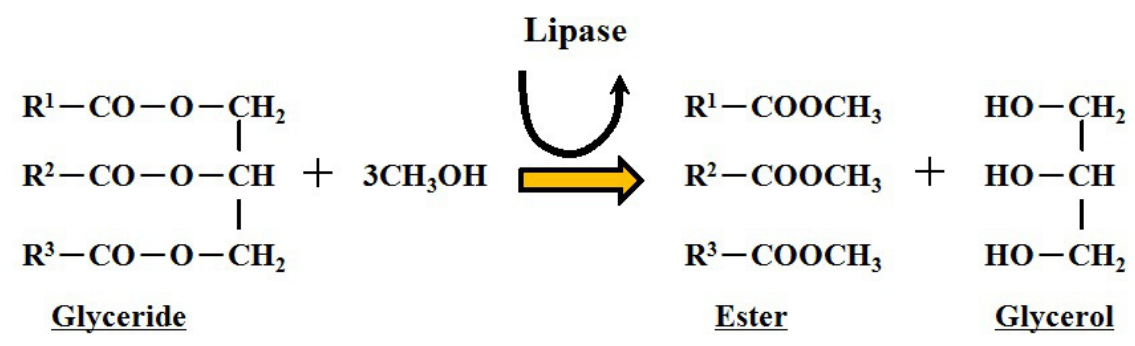

Figure 7. Esterification of triglyceride catalyzed by lipase

Nagayama, K. et al. investigated lecithin microemulsion-based organogels as immobilization carriers for the esterification of lauric acid with butyl alcohol catalyzed by Candida rugosa lipase [60]. Gelatin was used as the gelling component of the microemulsion-based organogels. The maximum reaction rate was obtained at a $G_{\mathrm{LW}}$ (volume fraction of water in microemulsion-based organogel) of $75 \% \mathrm{v} / \mathrm{v}$, a gelatin content of $18.5 \% \mathrm{w} / \mathrm{v}$, and a lecithin concentration of $18 \mathrm{mM}$. The reaction proceeded under a reaction-controlled regime, and the reaction rate was influenced by microemulsion-based organogel compositional changes. The effective diffusion coefficient of lauric acid varied with the microemulsion-based organogel composition, while that of butyl alcohol remained constant. The partition coefficient of both substrates was affected by the microemulsion-based organogel composition. Immobilized lipase was reused in a batch-reaction system, and its activity was successfully maintained for 720h. During repeated batch reactions, lipase activity was enhanced, while the ester concentration at $48 \mathrm{~h}$ was between 30 and $40 \mathrm{mM}$.

\subsection{Immobilized enzymatic reaction of soybean lipid modification}

Immobilization of lipase has been investigated to improve the stability and reusability of lipase in oil hydrolysis. For practical applications, a systematic strategy is necessary to select suitable support and organic solvents. Authors investigated a key factor of suitable support to improve enzyme activity and stability of immobilized lipase [61]. 


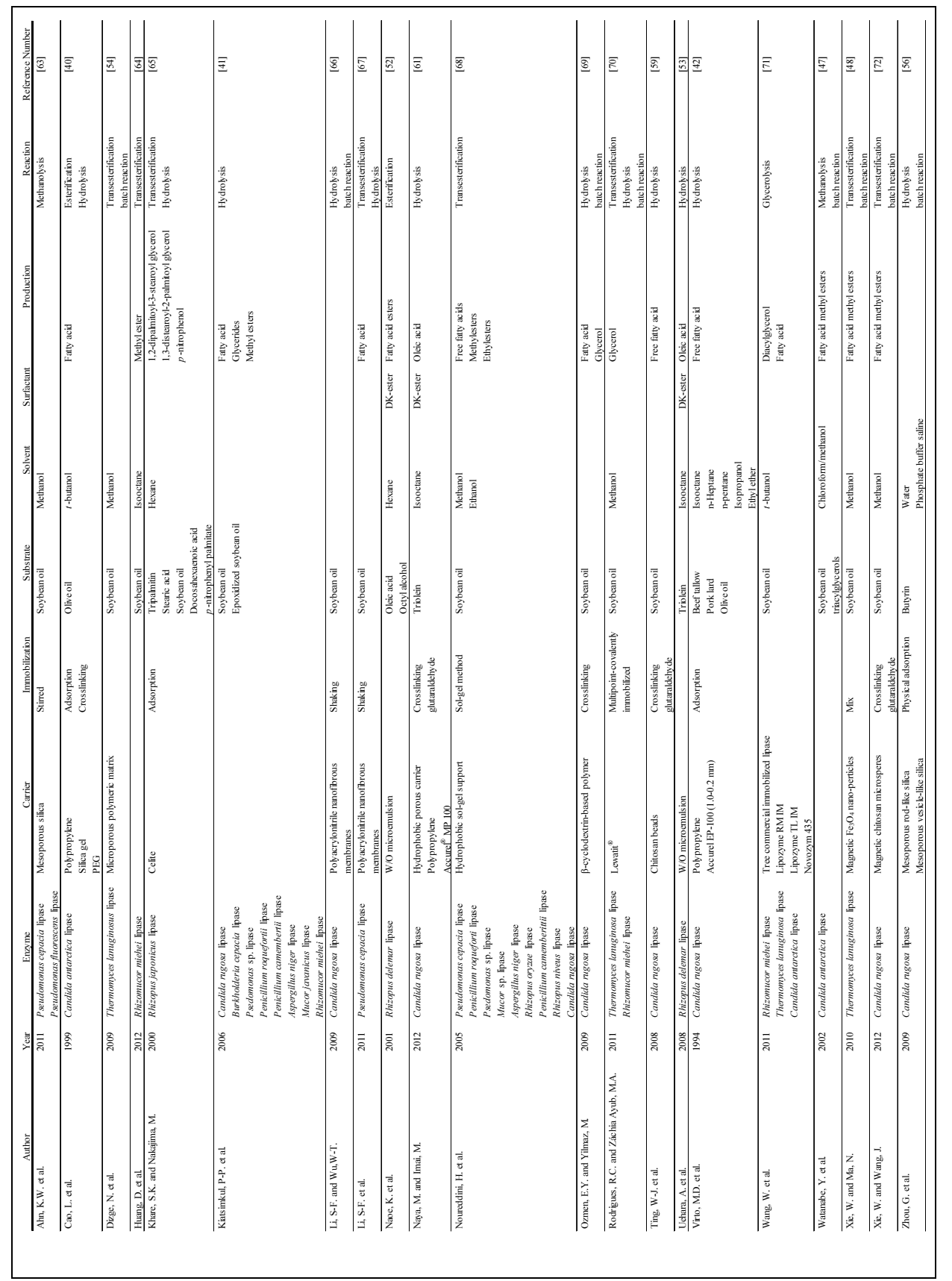

Table 5. Previous investigations of enzymatic lipid modification by lipase immobilized 
Immobilized enzymes have been examined for various industrial applications. In general, enzyme immobilization effectively enables separating the enzyme from products, thus facilitating their recovery and repeated use $[40,42,62]$. This is promising for industrial enzymatic production of various biomaterials. The main aspects of the currently investigated immobilized enzyme are as follows. First, the molecular structure of the enzyme is directly influenced by immobilization [50]. Second, enzyme reactivity is affected by the physicochemical characteristics of the enzyme carrier and the reaction media [40,51]. To quickly initiate hydrophobic enzymatic reactions, a water-in-oil (W/O) microemulsion system is desirable for achieving higher concentrations of hydrophobic substrate in the reaction media. Third, the diffusion of the substrate and the reaction products determines the rate-limiting condition in the reactivity of the immobilized enzyme [49]. Finally, repeated use of the immobilized enzyme in a practical process is a key factor in reducing costs in industrial applications.

Solid porous carriers are expected to resist compaction and deformation of carrier particles during practical use in bioreactors. Hydrophobic solid porous materials are preferred as immobilized enzymes for hydrophobic reactions. Table 5 summarizes previous hydrophobic substrate reactions using immobilized lipase. Hydrophobic materials, primarily a polypropylene porous commercial carrier called Accurel, have been employed for lipid hydrolysis and esterification. Lipase is adsorbed with strong multipoint interactions in Accurel [73]. Particle size plays a dominant role in determining the rate-limiting condition of the substrate $[46,49,55,74]$. The particle size as well as handling of particles was very important for both the practical design of the bioreactor and for determining reaction-rate-limiting conditions. In the Accurel EP-100 system, the effect of particle size on reaction rate was examined for a size range of 0.2 to $2.5 \mathrm{~mm}[49,55,62,74]$. A higher reaction rate was obtained for a smaller immobilized carrier. Sabbani et al. reported that the reaction rate was increased sixfold by decreasing the particle size from 0.2 to $1.5 \mathrm{~mm}$ [55]. Montero et al. pointed out that cross-linking of lipase (Candida rugosa) by glutaraldehyde (GA) was promising for attaining higher reaction activity [62]. Naya and Imai investigated lipid hydrolysis using an immobilized lipase on Accurel MP100 [61]. It examined the effect of particle size on the apparent reaction rate. The technical data were expected to be used in designs for industrial application of Accurel MP100 for hydrophobic immobilized lipase reactions.

\subsubsection{W/O microemulsion}

W/O microemulsions are spontaneous aggregates composed of amphiphilic molecules in non-polar media. The properties of reverse micelles have been extensively investigated in the field of reverse micellar techniques. Reverse micelles enable hydrophilic proteins to be solubilized in organic solvent and are anticipated to be used as separation and enzymatic reaction media with hydrophobic substrates. When enzymes are micro-encapsulated, they are situated inside the water pool of the W/O microemulsion; whether or not they interact with the micellar interface depends on the enzyme species (Fig. 8). For example, an enzyme reaction involving lipase was observed on the interfacial layer between the hydrophobic phase containing substrates, and the hydrophilic phase containing dissolved lipase. 


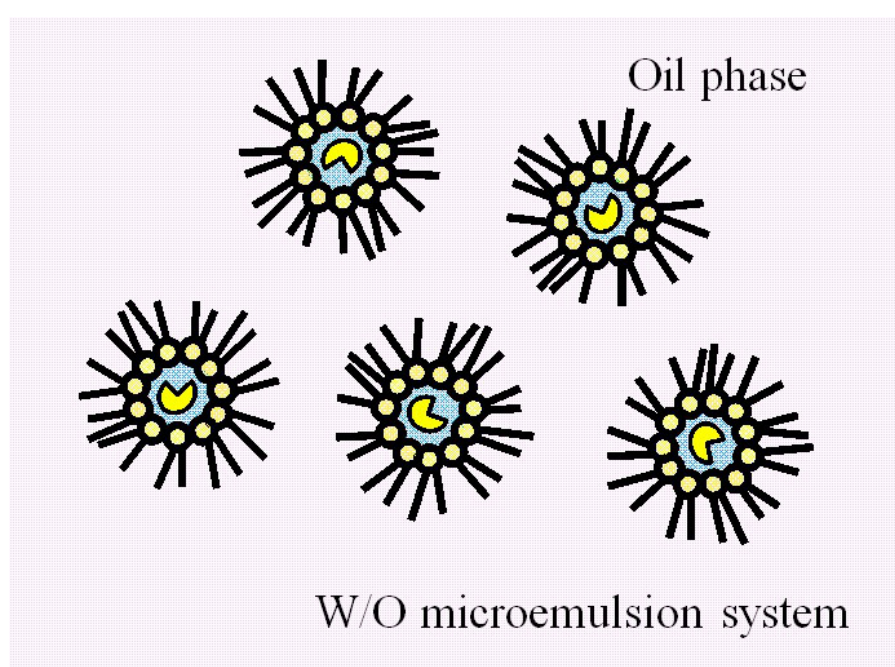

Figure 8. Schematic image of W/O microemulsion system. Micro-water pool was dispersed in bulk oil phase. 0 amphiphilic molecule. $\mathcal{O}$ :enzyme

Uehara et al. defined the reaction condition producing high reactivity over a limited range of both hydrophilicity and interfacial fluidity of the microemulsion droplet [53]. Their reaction condition was identified as the most favorable condition for sugar-ester alcohol W/O microemulsion media to perform lipid hydrolysis. The critical micelle concentration depended on the concentration of 1-butanol and was found to be inversely proportional to the second power of the 1-butanol concentration. The initial reaction rate of the hydrolysis of triolein in W/O microemulsion depended on the solubilized water content, reaching a maximum in the limited range of $2<\mathrm{W}_{\text {soln }}<4$. The maximum initial reaction rate increased about 2-fold following the addition of 1-butanol. The most favorable concentration of 1-butanol for hydrolysis by Rhizopus delemar was identified as 3.5\% v/v.

Naoe et al. investigated the esterification of oleic acid with octyl alcohol catalyzed by Rhizopus delemar lipase in a reverse micellar system of sugar ester DK-F-110 [52]. A high initial reaction rate was obtained by preparing a micellar organic phase with extremely low water content. The initial reaction rate decreased slightly with decreasing DK-F-110 concentration. The lipase exhibited $40 \%$ of its esterification activity after $28 \mathrm{~h}$ incubation in the DK-F-110 reverse micellar organic phase. Sodium bis(2-ethylhexyl)sulfosuccinate (AOT) is often used as an ionic amphiphilic molecule for reverse micelle formation owing to the advantages of spontaneous aggregation, thermodynamic stability, and non-additional co-surfactant. In the work of Naoe et al. the turnover number of the DK-F-110 system was larger than that of the system using AOT. 


\subsubsection{Gel beads carrier}

The major problem that must be solved to employ a microemulsion system in industrial processes is the recovery of the products and the repeated use of enzyme. Usual techniques such as extraction and distillation lead to poor separation because of the problems of emulsion-forming and foaming caused by the presence of surfactants. One approach to simplifying the recovery of the product and the enzyme for reuse from microemulsion based-media has been to employ gelled microemulsion systems. Interestingly, many W/O microemulsions can be gelled by adding gelatin, yielding a matrix suitable for enzyme immobilization. Cooling at room temperature causes a transparent gel with reproducible physical properties to form. These enzyme-containing, gelatin-based gels are rigid and stable in various non-polar organic solvents and may therefore be used for biotransformations in organic media. Under most conditions, the gel matrix fully retains the surfactant, gelatin, water, and enzyme components, allowing the diffusion of non-polar substrates or products between a contacting non-polar phase and the gel pellets.

Natural gelling agents such as gelatin, agar and $\kappa$-carrageenan have been tested for the formation of lecithin microemulsion-based gels as well as hydrogels presented by Stamatis, Hand Xenakis, A [75]. Lipase-containing microemulsions-based organogels formulated with various biopolymers have considerable potential for their application in biotransformations. Lipase immobilized in gelatin and agar organogels exhibited good stability in catalyzing esterification reactions under mild conditions with high conversion yields. High yields $(80 \%)$ were obtained with agar and $\kappa$-carrageenan organogels in isooctane. The remaining lipase activity in repeated syntheses was found to depend on the nature of the biopolymer used for forming the organogels. Gelatin and agar microemulsion-based gels had the highest operational stability. Moreover, aqueous gelatin and agar gels containing only lipase, water, and biopolymer retain their integrity in organic solvents and can also be used for the synthesis of esters.

Chitosan, poly [ $\beta$-(1-4)-linked-2-amino-2-deoxy-D-glucose], is non-toxic, hydrophilic, biocompatible, biodegradable, and anti-bacterial and can be used as a material for immobilized carriers since it has a variety of functional groups that can be tailored to specific applications. Xie, W. and Wang, J. investigated the effects of various transesterification parameters on the enzymatic conversion of soybean oil [72]. In their work, magnetic chitosan microspheres were prepared by the chemical co-precipitation approach using glutaraldehyde as the cross-linking reagent for lipase immobilization. Using the immobilized lipase, the conversion of soybean oil to fatty acid methyl esters reached $87 \%$ under the optimized conditions of a methanol/oil ratio of 4:1 with the three-step addition of methanol, reaction temperature $35^{\circ} \mathrm{C}$, and reaction time $30 \mathrm{~h}$. Moreover, the immobilized lipase could be used for four times without significant decrease of activity.

\subsubsection{Polypropylene carrier}

The immobilized lipase (Candida rugosa) using polypropylene-based hydrophobic granular porous carrier Accurel MP100 was investigated in lipid hydrolysis reactions involved in the effect of particle size on the apparent reaction rate [61]. The true shape of the original Accur- 
el was similar to a half cylinder (Fig. 9 (a)). Macro-pores existed near the particle surfaces. Inside the particle, the micro-pores formed many branched channels (Fig. 9 (b)).
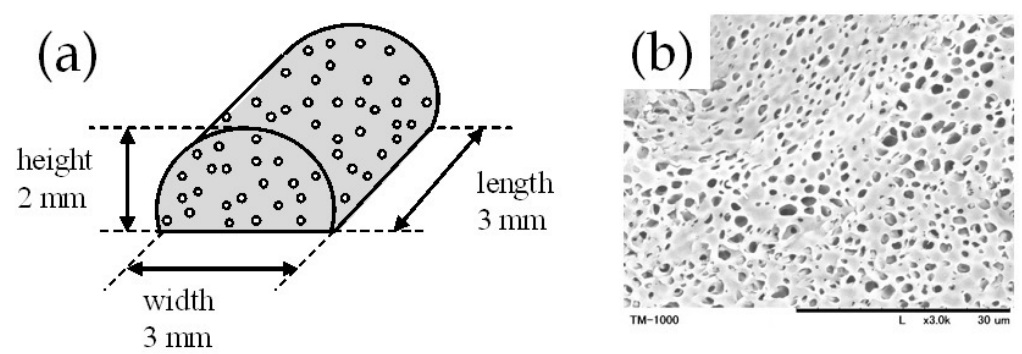

Figure 9. a). Schematic illustration of original Accurel MP100, a polypropylene-based hydrophobic granular support. The true shape of original Accurel particles seemed to be half cylinders. (b) SEM (electron microscopy) image of original Accurel particles.

The amount of immobilized lipase per unit mass of particle was increased by $19 \%$ in smaller particles $(500$ to $840 \mu \mathrm{m})$. The immobilized yield lipase based on the adsorbed amount was high (over 98\%) in every class of particle size (Fig. 10). Cross-linking of lipase by glutaraldehyde (GA) holds much promise for immobilization.

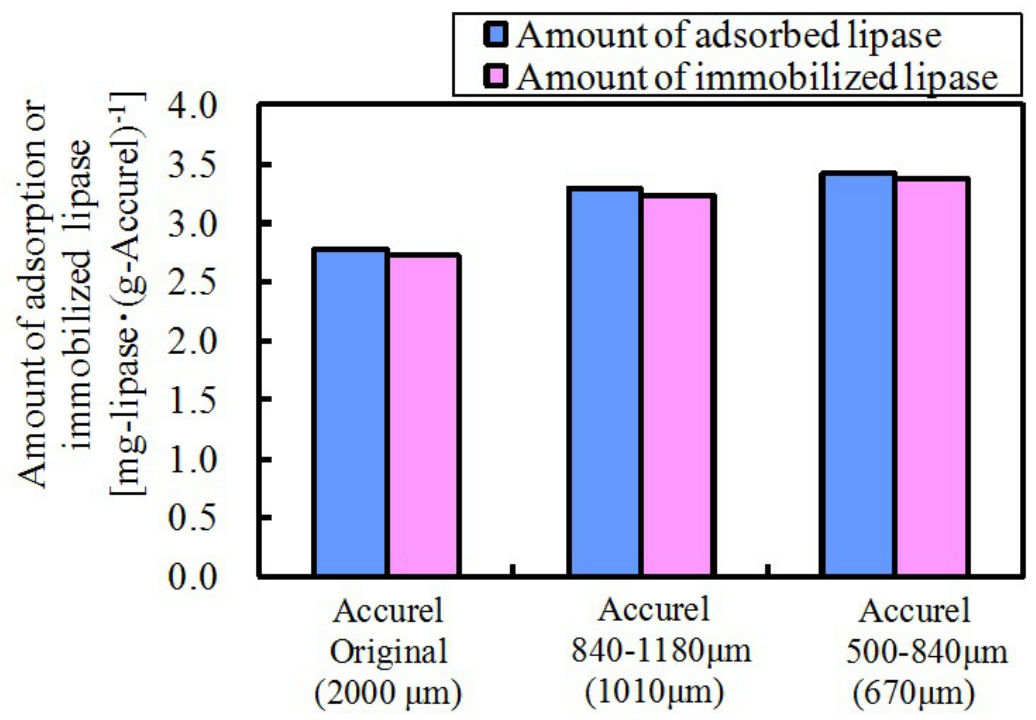

Figure 10. (a). Schematic illustration of original Accurel MP100, a polypropylene-based hydrophobic granular support. The true shape of original Accurel particles seemed to be half cylinders. (b) SEM (scanning electron microscopy) image of original Accurel particles. 
The reactivity of immobilized lipase as evaluated from the oleic acid production rate strongly depended on the Accurel particle size. In particular, the 500 to $840 \mu \mathrm{m}$ (mean diameter $670 \mu \mathrm{m})$ particles performed significantly outstanding reactivity compared with that of 840 to $1180 \mu \mathrm{m}$ (mean diameter $1010 \mu \mathrm{m}$ ) particles and original Accurel (Fig. 11). The experimental effectiveness factor was obtained and compared with the theoretical effectiveness factor. The difference was speculated to be due to assumptions of the geometrical factor of particles and the partition equilibrium of the substrate between the carrier particle and bulk phase. Quick initiation was observed in the repeated use of immobilized lipase on the 500 to 840 $\mu \mathrm{m}$ particles. The production yield was well-preserved.

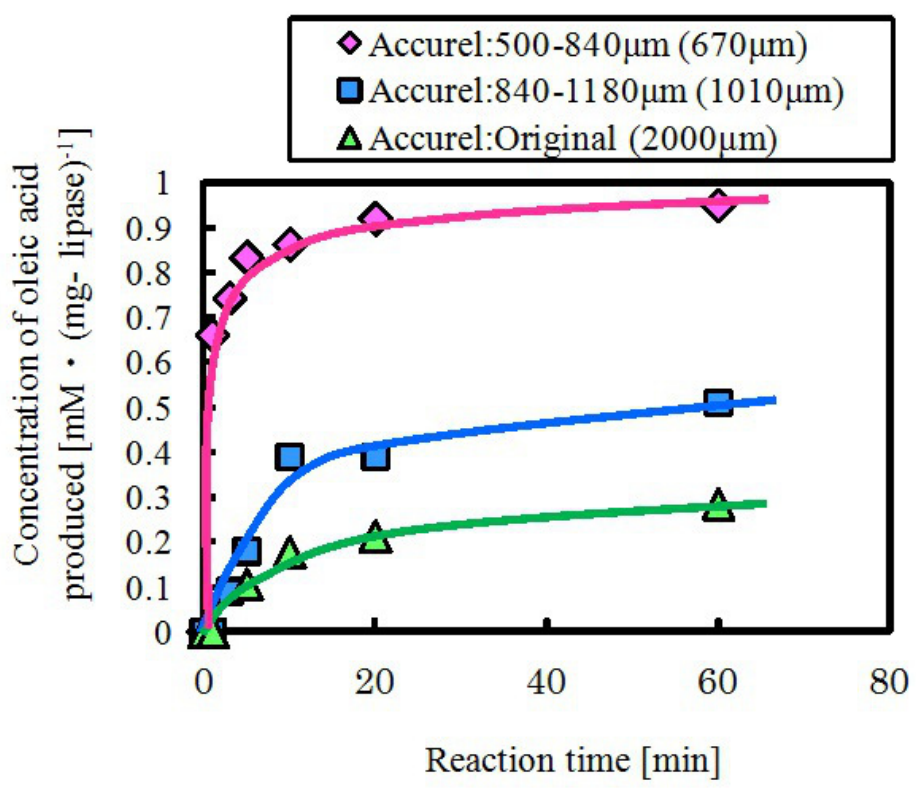

Figure 11. Comparison of reactivity of immobilized lipase for various particle sizes of Accurel.

\subsubsection{Nanofiber membrane}

Li, S-F. and $\mathrm{Wu}, \mathrm{W}-\mathrm{T}$. investigated immobilized lipase activity using a nanofiber membrane [66]. The activity retention of the immobilized lipase was $87.5 \%$ of the free enzyme. Under these optimal reaction conditions, the hydrolysis conversion of soybean oil was $72 \%$ after $10 \mathrm{~min}$ and $85 \%$ after $1.5 \mathrm{~h}$. In reusability, the immobilized lipase retained $65 \%$ of its initial conversion after 20 additional batch reactions. Protein loading reached $21.2 \mathrm{mg} / \mathrm{g}$ material of the membrane due to the large specific surface area provided by the nanofibers. This effective enzyme immobilization method has good potential for industrial applications. 


\subsection{Conclusion}

Soybean has been expected to be used both as a food and as a bioresource for attractive functional components. Soybean contains many proteins and much oil. Soybean oil can be hydrolyzed readily by lipase like other vegetable oils. The produced fatty acids find several applications such as in manufacturing soaps, surfactants, and detergents, and in food.

Immobilization of lipase has been investigated to improve its stability and reusability in oil hydrolysis. For practical applications, a systematic strategy is necessary to select suitable support and organic solvent. Since the novel developed method is promising, it could be used industrially for producing chemicals requiring immobilized lipases.

\section{Nomenclature}

$G_{\mathrm{LW}}$ : volume fraction of water in microemulsion-based organogel phase, referred from [60] (\% v/v microemulsion-based organogel phase)

Log P: hydrophobicity index by Laane et al. [34]. P was defined by partition equilibrium (-) $\mathrm{M}$ : molar fraction of ethanol in $\mathrm{SCCO}_{2}$, referred from [33] ([mol-Ethanol]/[mol-( $\mathrm{SCCO}_{2}+$ Ethanol)])

S: molar fraction of extracted sample in the $\mathrm{SCCO}_{2}$ and ethanol binary system, referred from [33] ] ([mol-extracted sample]/[mol-( $\mathrm{SCCO}_{2}+$ Ethanol)])

$\mathrm{W}_{\text {soln }}$ : molar ratio of solubilized water to amphiphile, referred from [53] ([mol- $\left.\mathrm{H}_{2} \mathrm{O}_{\text {soln }}\right] /[\mathrm{mol}-$ amphiphile])

$\alpha$ : the power term on the molar fraction of ethanol M, presented by Eq. (1), referred from [33]. It is summarized in Table $3(-)$

\section{Author details}

Masakazu Naya and Masanao Imai*

*Address all correspondence to: XLT05104@nifty.com

Course in Bioresource Utilization Sciences, Graduate School of Bioresource Sciences, Nihon University, Japan

\section{References}

[1] Izumi, T., Obata, A., Arii, M., Yamaguchi, H., \& Matsuyama, A. (2007). Oral Intake of Soy Isoflavone Improves the Aged skin of Adult Women. Journal of Nutritional Science and Vitaminology, 53, 57-62. 
[2] Lee, Y. B., Lee, H. J., Won, M. H., Hwang, I. K., Kang, T. C., Lee, J. Y., Nam, S. Y., Kim, K. S., Kim, E., Cheon, S. H., \& Sohn, H. S. (2004). Soy isoflavones Improve Spatial Delayed Matching-to-Place Peformance and Reduce Cholinergic Neuron Loss in Elderly Male Rats. The Journal of Nutrition, 134, 1827-1831.

[3] Lee, Y. B., Lee, H. J., Kim, K. S., Lee, J. Y., Nam, S. Y., Cheon, S. H., \& Sohn, H. S. (2004). Evaluation of the preventive Effect of Isoflavone Extract on Bone Loss in Ovariectomized Rats. Bioscience Biotechnology Biochemistry., 68(5), 1040-1045.

[4] Suh, K. S., Koh, G., Park, C. Y., Woo, J. T., Kim, S. W., Kim, J. W., Park, I. K., \& Kim, Y. S. (2003). Soybean isoflavones inhibit tumor facter- $\alpha$-induced apoptosis and production of interleukin-6 and prostaglandin $\mathrm{E}_{2}$ in osteoblastic cells. Phytochemistry., 63, 209-215.

[5] Mahesha, H. G., Singh, S. A., \& Rao, A. G. A. (2007). Inhibition of lipoxygenase by soy isoflavones: Evidence of isoflavones as redox inhibitors. Archives of Biochemistry and Biophysics, 461, 176-185.

[6] Chan, H. Y., Chan, H. Y., \& Leung, L. K. (2003). A potential mechanism of soya isoflavoes against 7,12-dimetylbenz[a]anthracene tumour inhibition. British Journal of Nutrition., 90, 457-465.

[7] Clubbs, E. A., \& Bomser, J. A. (2007). Glycitein activates extracellular signal-regulated kinase via vascular endothelial growth factor receptor signaling in nontumorigenic (RWPE-1) prostate epithelial cells. Journal of Nutritional Biochemistry., 18, 525-532.

[8] Murphy, P. A., Barua, K., \& Hauck, C. C. (2002). Solvent extraction selection in the determination of isoflavones in soy foods. Journal of Chromatography B., 777, 129-138.

[9] Luthria, D. L., Biswas, R., \& Natarajan, S. (2007). Comparison of extraction solvents and techniques used for the assay of isoflavones from soybean. Food Chemistry, 105, 325-333.

[10] Rostagno, M. A., Palma, M., \& Barroso, C. G. (2003). Ultrasound-assisted extraction of soy isoflavones. Journal of Chromatography A., 1012, 119-128.

[11] Rostagno, M. A., Palma, M., \& Barroso, C. G. (2007). Ultrasound-assisted extraction of isoflavones from beverages blended with fruit juices. Analytica Chimica Acta, 597, 265-272.

[12] Araújo, J. M. A., Silva, M. V., \& Chaves, J. B. P. (2007). Supercritical fluid extraction of daidzein and genistein isoflavones from soybean hypocotyls after hydrolysis with endogenous $\beta$-glucosidases. Food Chemistry., 105, 266-272.

[13] Kao, T. H., Chien, J. T., \& Chen, B. H. (2008). Extraction yield of isoflavones from soybeans cake as affected by solvent and supercritical carbon dioxide. Food Chemistry, $107,1728-1736$.

[14] Rostagno, M. A., Araújo, J. M. A., \& Sandi, D. (2002). Supercritical fluid extraction of isoflavones from soybean flour. Food Chemistry, 78, 111-117. 
[15] Yu, J., Liu, Y. F., Qiu, A. Y., \& Wang, X. G. (2007). Preparation of isoflavones enriched soy protein isolate from defatted soy hypocotyls by supercritical $\mathrm{CO}_{2}$. LWT-Food Science and Technology, 40, 800-806.

[16] Zuo, Y. B., Zeng, A. W., Yuan, X. G., \& Yu, K. T. (2008). Extraction of soybean isoflavones from soybean meal with aqueous methanol modified supercritical carbon dioxide. Journal of Food Engineering, 89, 384-389.

[17] Iwai, Y., Nagano, H., Lee, G. S., Uno, M., \& Arai, Y. (2006). Measurement of entrainer effect of water and ethanol on solubility in supercritical carbon dioxide by FT-IR spectroscopy. Journal of Supercritical Fluids., 38, 312-318.

[18] Johannsen, M., \& Brunner, G. (1994). Solubility of the xanthenes caffeine, theophylline and theobromine in supercritical carbon dioxide. Fluid Phase Equilibria., 95, 215-226.

[19] Kopcak, U., \& Mohamed, R. S. (2005). Caffeine solubilities in supercritical carbon dioxide/co-solvent mixtures. Journal of Supercritical Fluids., 34, 209-214.

[20] Li, S., Varadarajan, G. S., \& Hartland, S. (1991). Solubility of theobromine and caffeine in supercritical carbon dioxide: correlation with density-based models. Fluid Phase Equilibria., 68, 263-280.

[21] Duarte, C. M. M., Crew, M., Casimiro, T., Aguiar-Ricardo, A., \& Ponte, M. N. (2002). Phase equilibrium for capsaicin + water + ethanol + supercritical carbon dioxide. Journal of Supercritical Fluids, 22, 87-92.

[22] de la Fuente, J. C., Valderrama, J. O., Bottini, S. B., \& del Valle, J. M. (2005). Measurement and modeling of solubilities of capsaicin in high-pressure $\mathrm{CO}_{2}$. Journal of Supercritical Fluids, 34, 195-201.

[23] Cygnarowicz, M. L., Maxwell, R. J., \& Selder, W. D. (1990). Equilibrium solubility of $\beta$-carotene in supercritical carbon dioxide. Fluid Phase Equilibria, 59, 57-71.

[24] de la Fuente, J. C., Oyarzún, B., Quezada, N., \& del Valle, J. M. (2006). Solubility of carotenoid pigment (lycopene and astaxanthin) in supercritical carbon dioxide. Fluid Phase Equilibria, 247, 90-95.

[25] Škerget, M., Knez, Ž., \& Habulin, M. (1995). Solubility of $\beta$-carotene and oleic acid in dense $\mathrm{CO}_{2}$ and data correlation by a density based model. Fluid Phase Equilibria. , $109,131-138$.

[26] Subra, P., Castellani, S., Ksibi, H., \& Garrabos, Y. (1997). Contribution to the determination of the solubility of $\beta$-carotene in supercritical carbon dioxide and nitrous oxide: experimental data and modeling. Fluid Phase Equilibria, 131, 269-286.

[27] Berna, A., Cháfer, A., Montón, J. B., \& Subirats, S. (2001). High-pressure solubility data of system ethanol (1) + catechin (2) $+\mathrm{CO}_{2}$ (3). Journal of Supercritical Fluids, 20, 157-162. 
[28] Cháfer, A., Berna, A., Montón, J. B., \& Nuñoz, R. (2002). High-pressure solubility data of system ethanol (1) + epicatechin (2) $+\mathrm{CO}_{2}$ (3). Journal of Supercritical Fluids., 24, 103-109.

[29] Nunes, A. V. M., Matias, A. A., da Ponte, M. N., \& Duarte, C. M. (2007). Quaternary Phase Equilibria for $\mathrm{scCO}_{2}+$ Biophenolic Compound + Water + Ethanol. Journal of Chemical \& Engineering Data, 52, 244-247.

[30] Wang, L. H., \& Cheng, Y. Y. (2005). Solubility of Puerarin in Ethanol + Supercritical Carbon Dioxide. Journal of Chemical Engineering Data., 50, 1747-1749.

[31] Huang, Z., Chiew, Y. C., Lu, W. D., \& Kawi, S. (2005). Solubility of aspirin in supercritical carbon dioxide/alcohol mixture. Fluid Phase Equilibria, 237, 9-15.

[32] Matias, A. A., Nunes, A. V. M., Casimiro, T., \& Duarte, C. M. M. (2004). Solubility of coenzyme Q10 in supercritical carbon dioxide. J. of Supercritical Fluids., 28, 201-206.

[33] Nakada, M., Imai, M., \& Suzuki, I. (2009). Impact of ethanol addition on the solubility of various soybean isoflavones in supercritical carbon dioxide and the effect of glycoside chain in isoflavones. Journal of Food Engineering, 95, 564-571.

[34] Laane, C., Boeren, S., Vos, K., \& Veeger, C. (1987). Rules for optimization of biocatalysis in organic solvents. Biotechnology and Bioengineering, 30, 81-87.

[35] Paucar-Menacho, L. M., Amaya-Farfan, J., Berhow, M. A., Mandarino, J. M. G., Mejia, E. G., \& Chang, Y. K. (2010). A high-protein soybean cultivar contains lower isoflavones and saponins but higher minerals and bioactive peptides than a low-protein cultivar. Food Chemistry, 120, 15-21.

[36] Comas, D. I., Wagner, J. R., \& Tomas, M. C. (2006). Creaming stability of oil in water $(\mathrm{O} / \mathrm{W})$ emulsions: Influence of $\mathrm{pH}$ on soybean protein-lecithin interaction. Food Hydrocolloids, 20, 990-996.

[37] Berhow, M. A., Wagner, E. D., Vaughn, S. F., \& Plewa, M. J. (2000). Characterization and antimutagenic activity of soybean saponins. Mutation Research, 448, 11-22.

[38] Viana, P. A., Rezende, S. T., Falkoski, D. L., Leite, T. A., Jose, I. C., Moreira, M. A., \& Guimaraes, V. M. (2007). Hydrolysis of oligosaccharides in soybean products by Debaryomyces hansenii UFV-1 $\alpha$-galactosidases. Food Chemistry., 103, 331-337.

[39] Wang, Q., Ying, T., Jahangir, M. M., \& Jiang, T. (2012). Study on removal of coloured impurity in soybean oligosaccharides extracted from sweet slurry by adsorption resins. Journal of Food Engineering, in press.

[40] Cao, L., Bornscheuer, U. T., \& Schmid, R. D. (1999). Lipase-catalyzed solid-phase synthesis of sugar esters. Influence of immobilization on productivity and stability of the enzyme. Journal of Molecular Catalysis B: Enzymatic, 6, 279-285.

[41] Kiatsimkul-P, P., Sutterlin, W. R., \& Suppes, G. J. (2006). Selective hydrolysis of epoxidized soybean oil by commercially available lipases: Effects of epoxy group on the enzymatic hydrolysis. Journal of Molecular Catalysis B: Enzymatic., 41, 55-60. 
[42] Virto, M. D., Agud, I., Montero, S., Blanco, A., Solozabal, R., Lascaray, J. M., Llama, M. J., Serra, J. L., Landeta, L. C., \& Renobales, M. (1994). Hydrolysis of animal fats by immobilized Candida rugosa lipase. Enzyme and Microbial Technology., 16, 61-65.

[43] Hita, E., Robles, A., Camacho, B., Gonzalez, P. A., Esteban, L., Jimenez, M. J., Munio, M. M., \& Molina, E. (2009). Production of structured triacylglycerols by acidolysis catalyzed by lipases immobilized in a packed bed reactor. Biochemical Engineering Journal, 46, 257-264.

[44] Jimenez, M. J., Esteban, L., Robles, A., Hita, E., Gonzalez, P. A., Munio, M. M., \& Molina, E. (2010). Production of triacylglycerols rich in palmitic acid at sn-2 position by lipase-catalyzed acidolysis. Biochemical Engineering Journal, 51, 172-179.

[45] Pilarek, M., \& Szewczyk, K. W. (2007). Kinetic model of 1,3-specific triacylglycerols alcoholysis catalyzed by lipases. Journal of Biotechnology, 127, 736-744.

[46] Salis, A., Sanjust, E., Solinas, V., \& Monduzzi, M. (2003). Characterisation of Accurel MP1004 polypropylene powder and its use as a support for lipase immobilization. Journal of Molecular Catalysis B: Enzymatic., 24-25, 75-82.

[47] Watanabe, Y., Shimada, Y., Sugihara, A., \& Tominaga, Y. (2002). Conversion of degummed soybean oil to biodiesel fuel with immobilized Candida antarctica lipase. Journal of Molecular Catalysis B: Enzymatic., 17, 151-155.

[48] Xie, W., \& Ma, N. (2010). Enzymatic transesterification of soybean oil by using immobilized lipase on magnetic nano-particles. Biomass and Bioenergy, 34, 890-896.

[49] Salis, A., Svensson, I., Monduzzi, M., Solinas, V., \& Adlercreutz, P. (2003). The atypical lipase B from Candida antarctica is better adapted for organic media than the typical lipase from Thermomyces lanuginose. Biochimica et Biophysica Acta., 1646, 145-151.

[50] Palomo, J. M., Fernandez-Lorente, G., Mateo, C., Ortiz, C., Fernandez-Lafuente, R., \& Guisan, J. M. (2002). Modulation of the enantioselectivity of lipases via controlled immobilization and medium engineering: hydrolytic resolution of mandelic acid esters. Enzyme and Microbial Technology, 31, 775-783.

[51] Persson, M., Mladenoska, I., Wehtje, E., \& Adlercreutz, P. (2002). Preparation of lipases for use in organic solvents. Enzyme and Microbial Technology, 31, 833-841.

[52] Naoe, K., Ohsa, T., Kawagoe, M., \& Imai, M. (2001). Esterification by Rhizopus delemar lipase in organic solvent using sugar ester reverse micelles. Biochemical Engineering Journal, 9, 67-72.

[53] Uehara, A., Imai, M., \& Suzuki, I. (2008). The most favorable condition for lipid hydrolysis by Rhizopus delemar lipase in combination with a suger-ester and alcohol W/O microemulsion system. Colloids and Surfaces A: Physicochemical and Engineering Aspects, 324, 79-85.

[54] Dizge, N., Aydiner, C., Imer, D. Y., Bayramoglu, M., Tanriseven, A., \& Keskinler, B. (2009). Biodiesel production from sunflower, soybean, and waste cooking oils by 
transesterification using lipase immobilized onto a novel microporous polymer. Bioresource Technology., 100, 1983-1991.

[55] Sabbani, S., Hedenstrom, E., \& Nordin, O. (2006). The enantioselectivity of Candida rugosa lipase is influenced by the particle size of the immobilising support material Accurel. Journal of Molecular Catalysis B: Enzymatic., 42, 1-9.

[56] Zhou, G., Chen, Y., \& Yang, S. (2009). Comparative studies on catalytic properties of immobilized Candida rugosa lipase in ordered mesoporous rod-like silica and vesicle-like silica. Microporous and Mesoporous Materials, 119, 223-229.

[57] Dalla, Rosa. C., Morandim, M. B., Ninow, J. L., Oliveira, D., Treichel, H., \& Vladimir, Oliveira. J. (2009). Continuous lipase-catalyzed production of fatty acid ethyl esters from soybean oil in compressed fluids. Bioresource Technology, 100, 5818-5826.

[58] Guan, F., Peng, P., Wang, G., Yin, T., Peng, Q., Huang, J., Guan, G., \& Li, Y. (2010). Combination of two lipases more efficiently catalyzes methanolysis of soybean oil for biodiesel production in aqueous medium. Process Biochemistry, 45, 1677-1682.

[59] Ting , W. J., Huang, C. M., Giridhar, N., \& Wu, W. T. (2008). An enzymatic/acid-catalyzed hybrid process for biodiesel production from soybean oil. Journal of the Chinese Institute of Chemical Engineering, 39, 203-210.

[60] Nagayama, K., Yamasaki, N., \& Imai, M. (2002). Fatty acid Esterification catalyzed by Candida rugosa lipase in lecithin microemulsion-based organogels. Biochemical Engineering Journal, 12, 231-236.

[61] Naya, M., \& Imai, M. (2012). Regulation of the hydrolysis reactivity of immobilized Candida rugosa lipase with the aid of a hydrophobic porous carrier. Asia-Pacific Journal of Chemical Engineering, 7(S1), S157-S165.

[62] Montero, S., Blanco, A., Virto, M. D., Landeta, L. C., Agud, I., Solozabal, R., Lascaray, J. M., Renobales, M., de Llama, M. J., \& Serra, J. L. (1993). Immobilization of Candida rugosa lipase and some properties of the immobilized enzyme. Enzyme and Microbial Technol., 15, 239-247.

[63] Ahn, K. W., Ye, S. H., Chun, W. H., Rah, H., \& Kim, S. G. (2011). Yield and component distribution of biodiesel by methanolysis of soybean oil with lipase-immobilized mesoporous silica. Microporous and Mesoporous Materials, 142, 37-44.

[64] Huang, D., Han, S., Han, Z., \& Lin, Y. (2012). Biodiesel production catalyzed by Rhizomucor miehei lipase-displaying Pichia pastoris whole cells in an isooctane system. Biochemical Engineering Journal, 63, 10-14.

[65] Khare, S. K., \& Nakajima, M. (2000). Immobilization of Rhizopus japonicas lipase on celite and its application for enrichment of docosahexaenoic acid in soybean oil. Food Chemistry., 68, 153-157.

[66] Li, S. F., \& Wu, W. T. (2009). Lipase-immobilized electrospun PAN nanofibrous membranes for soybean oil hydrolysis. Biochemical Engineering Journal, 45, 48-53. 
[67] Li, S. F., Fan, Y. H., Hu, R. F., \& Wu, W. T. (2011). Pseudomonas cepacia lipase immobilized onto the electrospun PAN nanofibrous membranes for biodiesel production from soybean oil. Journal of Molecular Catalysis B: Enzymatic., 72, 40-45.

[68] Noureddini, H., Gao, X., \& Philkana, R. S. (2005). Immobilized Pseudomonas cepacia lipase for biodiesel fuel production from soybean oil. Bioresource Technology, 96, 769-777.

[69] Ozmen, E. Y., \& Yilmaz, M. (2009). Pretreatment of Candida rugosa lipase with soybean oil before immobilization on $\beta$-cyclodextrin-based polymer. Colloids and Surfaces B: Biointerfaces., 69, 58-62.

[70] Rodrigues, R. C., \& Záchia, Ayub. M. A. (2011). Effects of the combined use of Thermomyces lanuginosus and Rhizomucor miehei lipases for the transesterification and hydrolysis of soybean oil. Process Biochemistry, 46, 682-688.

[71] Wang, W., Li, T., Ning, Z., Wang, Y., Yang, B., \& Yang, X. (2011). Production of extremely pure diacylglycerol from soybean oil by lipase-catalyzed glycerolysis. Enzyme and Microbial Technology, 49, 192-196.

[72] Xie, W., \& Wang, J. (2012). Immobilized lipase on magnetic chitosan microspheres for transesterification of soybean oil. Biomass and Bioenergy, 36, 373-380.

[73] Gitlesen, T., \& Bauer, M. (1997). Adlercreutz, P., Adsorption of lipase on polypropylene powder. Biochimica et Biophysica Acta., 1345, 188-196.

[74] Al-Duri, B., \& Yong, Y. P. (1997). Characterisation of the equilibrium behavior of lipase PS (from Pseudomonas) and lipolase 100L (from Humicola) onto Accurel EP100. Journal of Molecular Catalysis B: Enzymatic., 3, 177-188.

[75] Stamatis, H., \& Xenakis, A. (1999). Biocatalysis using microemulsion-based polymer gels containing lipase. Journal of Molecular Catalysis B: Enzymatic, 6, 399-406. 